\title{
How to teach optics for the second time
}

\section{Adolf Lohmann}

Adolf W. Lohmann, "How to teach optics for the second time," Proc. SPIE 3831, Sixth International Conference on Education and Training in Optics and Photonics, (16 June 2000); doi: 10.1117/12.388712 


\title{
How to Teach Optics for the Second Time
}

\author{
Adolf W. Lohmann \\ University of Erlangen, Telecommunications Dept., Cauer St. 7, 91058 Germany
}

\begin{abstract}
Most students of physics and engineering are exposed to optics for the first time during their final year in high school and/or during their first year in college. That first encounter is brief and superficial, in most cases. Hence, those students might have a negative prejudice against optics, when having to select advanced courses during their second and third year in college. If we, the optics professors, want to attract the brightest students as our junior researchers, we ought to offer an exciting and challenging "introduction to the fundamentals of optics" for the advanced under graduate students in a way that eliminates any negative prejudices already during the first hour of the course. To start the course with Snellius, with the lens equation, and with similar primitive issues would chase away many of the brightest students.
\end{abstract}

\section{The scenario}

Every professor wants to attract the best students for his research team. How to do that? Many colleges offer for second and third year students "obligatory selective courses". A student has to sign up for two out of five possible courses. The chances are high that one of those two selected courses will be the base for the research work later on.

University curricula vary widely, of course. But it is a fairly universal fact that an optics professor is competing with other non-optics professors for getting good students. Those students will often base their decision on their course experiences roughly in the middle of the under graduate years. When I taught such an "attracting" course I emphasized the fundamentals for reasons explained at an earlier ETOP meeting in 1991 [1].

In the following chapters I will sketch how I address: "What is light" (2); "Geometrical optics" (3); "Wave optics" (4); and "some how to teach suggestions" (5).

\section{What is Light}

Does light consist of rays, or of waves, or of photons? We have to live with that inconsistency, perhaps our brain is not good enough for getting a unique and consistent answer to the "what is"-question. A consolation: quantum mechanics is also schizophrenic. In other words: the duality of waves and particles is a universal dilemma in physics. Let us be modest: "what is" cannot be answered in science. The philosophic school of "positivists" (with Mach, Kirchhoff and others) has clarified the situation already more than 100 years ago, leaving the "what 
is"-question to be dealt with by philosophers and theologians. The best we can hope for is a consistent and convenient description of nature, not an "explanation".

\section{Geometrical Optics}

I hated geometrical optics when I was a junior student because the intellectual platform (laws of Snellius; reflection) is so small, and the calculation of a simple setup (say image formation with prescribed magnification, and with two given lenses) is so tedious. Here is how I propose to begin with teaching geometrical optics.

Pierre De Fermat (1601-1665) was a French aristocrat with many professions: lawyer, politician, philosopher, mathematician, and optician. He lived during the "thirty-year-war" (1618-1648), while the population of central Europe was reduced from 8 millions to 2 millions. Fermat had a marvelous intuition. In mathematics he predicted that the following equation could not be solved with integers $(\mathrm{x}, \mathrm{y}, \mathrm{z})$ :

$$
x^{n}+y^{n}=z^{n}(n>2)
$$

Fermat scribbled onto the margin of his proposition paper something like: "The proof is trivial, but a bit too long for this piece of paper". Many generations of mathematicians worked on "Fermat's last lemma", until Andrew Wiles solved the puzzle in 1995. Why am I telling this obscure piece of number theory? Partially, because number theory has influenced science and engineering in many ways, recently [2], perhaps soon in optics as well. Sometimes, very abstract concepts, like Fermat's intuitive proposition, have very practical consequences.

After having celebrated Fermat as a mathematician, I would present Fermat's proposition about ray optics, and consequences thereof. I would discuss the special cases of "extremum": minimum, maximum, and degeneracy(=focusing).

$$
\int_{A}^{B} n(s) d s=\text { Extremum }
$$

Respect for Fermat will spill over to respect for the fundamentals of ray optics, most likely.

The dreadful lens equation would have to be mentioned of course, but I would proceed quickly to the matrix formulation of ray optics. Students will be pleased to realize that their abstract math courses on vectors and matrices are useful after all.

\section{Wave Optics}

I would again start with some biographic motivation, for example by telling the life story of Ernst Abbe [3]. Before entering wave optics per se, I would teach Fourier mathematics, as shown for example in the first 60 pages of my lecture notes [3]. I know that all of my students have been exposed already to Fourier (whose life story is also worth telling) by math professors. But Fourier math is so enormously important that it has to be taught twice, in different styles. I use Moire experiments for illustration and stimulation. 


\section{Some "How to Teach" - Suggestions}

An important question is: How much math? Some theoretical physicists or system theoreticians make life simple for themselves by teaching a course, which is in reality math in disguise. Many suitable texts exist for that purpose. The design and test of homework is easy. Other professors make the opposite mistake by avoiding math altogether. They are afraid to lose students. He complexity of their courses ends at $\sin \alpha=\lambda / D$, or similar. Really good students like to be challenged, if the motivation for the mathematical tools and for the homework problems is credible.

Shall one distribute lecture notes? In my opinion: only as a table of facts (like numerical values of basic constants, or as a reminder of some Fourier tools, such as convolution, cross correlation, Parceval). Similarly, shall one recommend a textbook and stick to it closely? I never did it because I wanted my students to be active during class hours, taking notes. Passive listening does not stick very well in the memory. But I would recommend supplementary reading, for example the extraordinary well illustrated book "What is Light?" [4]. By the way, it is a mistake in my opinion to project figures as viewgraphs. The teacher should draw by hand on a blackboard, giving the student a chance to produce his own figure. For example, the sequence of graphical elements is instructive. I tend to do it in realistic fashion, starting with the optical axis (the rail), then positioning the lenses. Next I draw the light source. Switching it on corresponds to drawing rays from the source to the receiver. Those steps are accompanied by "experimental" remarks. An attentive student, when in the laboratory, will not start by switching on the laser, which might be dangerous. Hence, I am able to teach "laser safety" in a "by-the-way"-fashion.

Basically, I believe teaching optics is easy because it is - and it corresponds to - a visual process, which is the most effective pathway into our brains.

\section{References}

[1] A. W. Lohmann, "Looking forward: Teaching optics in the twenty-first centurty," SPIE 1603 (1991) 52.

[2] M. R. Schroeder, "Number theory with applications in science and engineering," Springer, Heidelberg, second edition, 1986.

[3] A. W. Lohmann: Lecture notes on "Optical information processing," published by the author. Especially pp. 140-144.

[4] A. C. S. Van Heel, C. H. F. Velzel, "What is light?" world university library, McGraw-Hill, 1968. 